\title{
Diagnóstico Ambiental da Unidade de Conservação do Banhado em São José dos Campos/SP
}

Environmental diagnosis of the Banhado conservation unit in São José dos Campos/SP

Diagnóstico Ambiental de la Unidad de Conservación del bañado en São José dos Campos / SP

Cleiton Evaldo Mendes

Mestre em Ciências Ambientais pela Universidade Brasil, Brasil cleiton.mendes32@gmail.com

\section{Gisele Herbst Vazquez}

Professora Doutora Universidade Brasil, Brasil gisele.vazquez@universidadebrasil.edu.br

Andrea Penha Gregório Vasconcelos Mestre em Ciências Ambientais pela Universidade Brasil, Brasil andreapenha@gmail.com 

Por sua vez, no início do novo milênio o grande desafio da humanidade é conviver com a baixa disponibilidade de água causada pelo uso excessivo e poluição dos corpos hídricos, sejam elas naturais ou provocadas pelo homem (LUCAS et al., 2010).

\section{OBJETIVO}

O objetivo deste trabalho foi realizar um diagnóstico ambiental da unidade de conservação do Banhado em São José do Rio Preto/SP, bem como avaliar a qualidade das hortaliças produzidas.

\section{METODOLOGIA}

São José dos Campos está localizado entre as duas principais metrópoles brasileiras, São Paulo e Rio de Janeiro, possuindo uma população estimada em 2017 de 703.219 pessoas e de 629.921 pessoas em 2010 de acordo com o Instituto Brasileiro de Geografia e Estatística (IBGE, 2017). O local deste estudo limitou-se a área de produção de hortaliças e comunidade Jardim Nova Esperança, ambas na UC do Banhado, em São José dos Campos/SP, na planície aluvial do rio Paraíba do Sul. Por ser uma área perigosa pela presença de traficantes de drogas (G1 VALE DO PARAÍBA E REGIÃO, 2014), foi necessária uma autorização dos posseiros e residentes locais para a entrada no local e a coleta de amostras para a execução desta pesquisa.

\section{Avaliações}

Amostras de solo foram coletadas em 27/09/2017, sendo o primeiro ponto (P1) em uma área de cultivo de hortaliças, atividade comercial desenvolvida há mais de 40 anos por posseiros e o segundo (P2), a cerca de $350 \mathrm{~m}$ do P1 em um local próximo as habitações do Jardim Nova Esperança (Figura 1), existente há mais de 80 anos.

Em cada local de amostragem do solo (horta e Jd. Nova Esperança), como as áreas eram bem homogêneas, as amostras foram compostas de três subamostras coletadas a 0-20 cm de profundidade com uma pá de corte. As características químicas do solo avaliadas foram: umidade, pH, teores de nitrogênio total, fósforo, potássio, cálcio, magnésio, zinco, boro, ferro, cobre e manganês. As análises foram realizadas no laboratório de Tecnologia Ambiental AMBIOTEC de São José dos Campos/SP.

Para as determinações das características físicas, químicas e biológicas da qualidade da água, no dia 27/09/2017 às 10:30 h uma amostra da principal fonte hídrica utilizada para a irrigação das hortaliças pelos agricultores foi coletada. No ponto de captação foi coletada $1.000 \mathrm{~mL}$ de água, que após identificação, foi transportada sob condições de refrigeração utilizando-se uma caixa isotérmica contendo gelo a temperatura de $4^{\circ} \mathrm{C}$, estando todo o procedimento de acordo com o plano de amostragem descrito no Standard Methods for the Examination of Water and Wastewater (APHA et al., 2012). A amostra foi encaminhada para o laboratório de Tecnologia Ambiental - AMBIOTEC de São José dos Campos/SP. 


\section{Determinação da matriz SWOT}

Para o diagnóstico ambiental, foi utilizada a metodologia de SWOT assumida por suas siglas em português como matriz FOFA (strengths/forças, weaknesses/fraquezas, opportunities/oportunidades, threats/ameaças), que é uma ferramenta alternativa que possibilita a avaliação de um cenário ou de algum ambiente. Para tanto, após algumas visitas no local foram identificados fatores para cada um dos indicadores: forças e fraquezas (fatores internos); oportunidades e ameaças (fatores externos).

\section{RESULTADOS}

Os solos originais do Banhado eram latossolos cobertos por florestas pluviais, hidromórficos, que após séculos de uso inadequado e aterros sucessivos estão pobres, arenosos, lixiviados e compactados em sua maioria, fruto da ação antrópica (MMA, 2018). Embora tenha perdido sua função de captar as águas nas épocas de cheia do rio (em virtude da construção das represas de rios formadores do Paraíba do Sul, Paraibuna e Paraitinga, em 1974, as quais regulam o nível das águas do Paraíba), a área do Banhado ainda corresponde a uma planície inundável e de alta fragilidade, devido às características de seu solo inconsolidado (FLORIANO, 2009).

A região do Banhado era originalmente ocupada por Florestas Estacional Semidecidual Aluvial, (bioma Mata Atlântica), que precedentemente à ocupação humana intensiva, se estendia por sobre a planície aluvial do rio Paraíba do Sul (Morelli et al., 2003). Era recoberta por um rico conjunto de ecossistemas de áreas alagáveis de grande biodiversidade (SANTOS et al., 2015).

Porém, a vegetação original foi suprimida de uma só vez no século XIX para a construção e operação da Estrada de Ferro Central do Brasil, e posteriormente, no início do século XX, pelas atividades agrícolas que motivaram a construção de canais de drenagem pelo Departamento de Águas e Energia Elétrica (DAEE) (MORELLI, 2002).

Neste período, com a regularização das cheias e a água proporcionada pelo sistema de diques foi possível o aproveitamento das várzeas do rio Paraíba, especialmente pela rizicultura, o que tornou a área produtiva e disputada por agricultores, especuladores imobiliários e pela indústria extrativa, destacadamente os areeiros (SANTOS et al., 2015). A partir da década de 1970, o Banhado foi alvo de uma série de planejamentos não concretizados como loteamentos, parque temático e parque ecológico, tendo sido decretada como APA Municipal em 1984, APA Estadual em 2002 e como Parque Natural Municipal em 2012.

O Parque Natural Municipal do Banhado (PNMB) tem os mesmos objetivos e prerrogativas legais que os parques naturais nacionais, porém, com o diferencial de ter sido instituído pela Prefeitura de São José dos Campos, que delimitou seu perímetro como parte da então já instaurada APA Estadual do Banhado. A APA do Banhado possui 520 ha (sendo 53,2 ha, terras públicas) situada no centro da cidade, mas inicialmente o Núcleo da Unidade de Conservação e Proteção Integral, ou seja, o PNMB, foi delimitado em 151,5 ha (PREFEITURA, 2017; SILVA et al., 2017), havendo, portanto, sobreposição das áreas (Figura 2). 


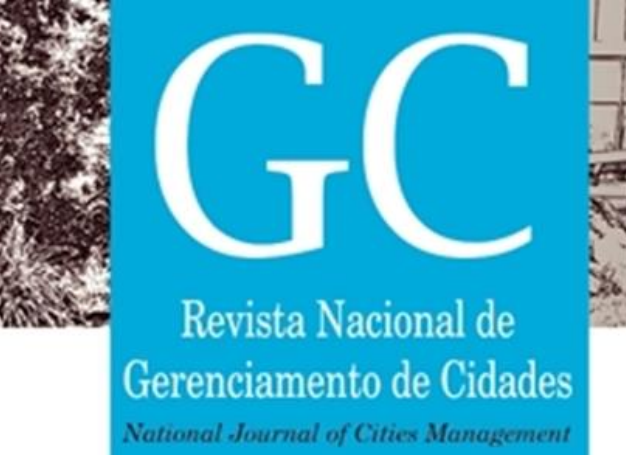

Figura 2: Área da APA Estadual do Banhado e do Parque Municipal do Banhado (sobreposição das áreas)

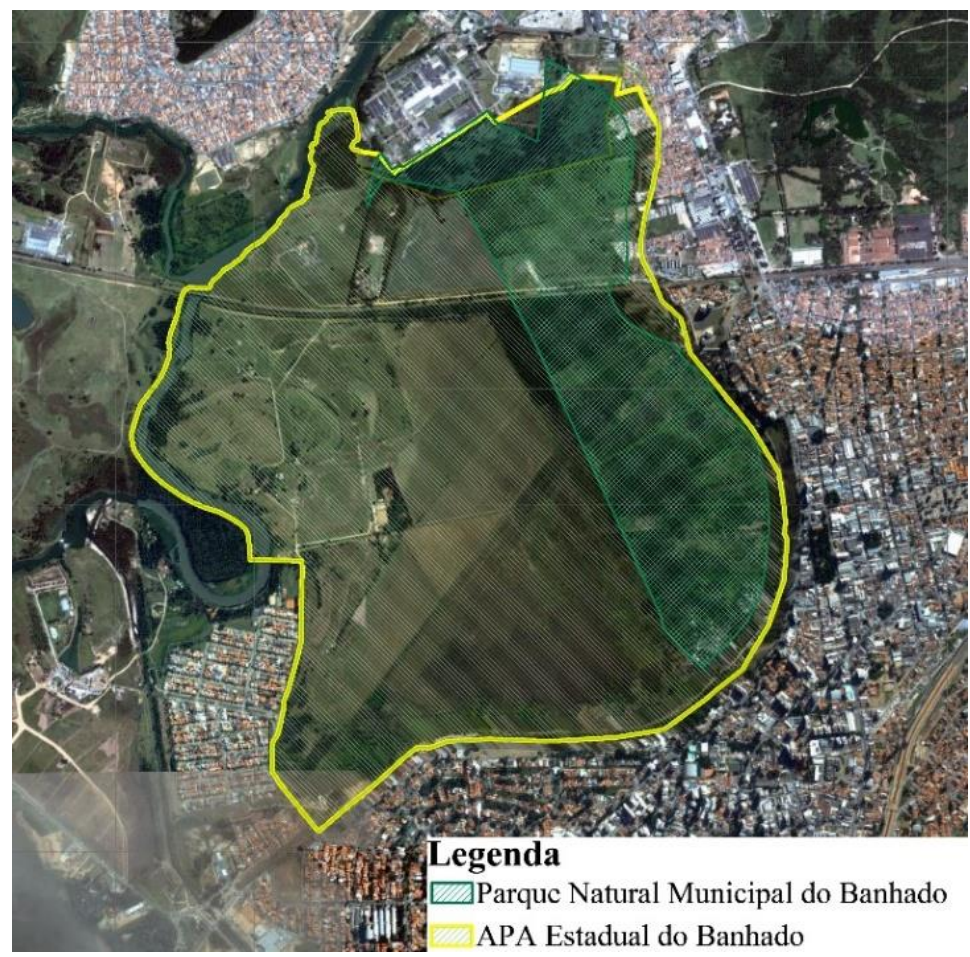

Fonte: Google Maps (2018)

Com sua criação, o uso e ocupação de parte da APA do Banhado tornaram-se mais restritivos, dado que os Parques Naturais constituem categoria de UC mais restritiva que as APAs. Diversas novas condições foram impostas a partir da criação dessa nova UC, tais como a readequação de infraestrutura, novos mecanismos de fiscalização e gestão, ordenamento espacial e de ocupação humana. A administração da área passou a ser de responsabilidade da Secretaria de Meio Ambiente (SEMEA) de São José dos Campos, sendo vedadas as seguintes atividades: o parcelamento do solo para fins urbanos; a instalação de indústria poluente; a ampliação da área das indústrias existentes; o uso de técnicas de manejo do solo capazes de provocar a erosão das terras ou o assoreamento dos cursos d'água; a remoção da cobertura vegetal existente; a exploração mineral e a utilização da área para chácaras de recreio.

Assim, desde 2006 a Prefeitura de São José dos Campos estuda remover as famílias que habitam desde 1931 parte da área do Banhado, visto ser esta uma exigência ambiental, onde em uma Unidade de Proteção Integral não é permitido moradores. O local possui abastecimento de água precário e sem tratamento, sendo a destinação do esgoto feita por fossa séptica.

Com relação à caracterização química do solo da área do Banhado, os dados apresentados na Tabela 1 evidenciam que não há contaminação, segundo os parâmetros avaliados de zinco e cobre segundo a Resolução no 420 do CONAMA (2009) e da CETESB (2014). 
O ponto $\mathrm{P} 1$, por ser uma área de horta constantemente adubada com matéria orgânica (esterco curtido), apresentou uma maior fertilidade do solo que a do ponto P2. Além disso, a menor fertilidade da amostra de solo no ponto P2 também pode estar associada ao desmatamento da área para a instalação dos "barracos" do Jardim Nova Esperança (Tabela 1).

Tabela 1: Avaliação da qualidade do solo (P1- horta e P2 - Jd. Nova Esperança) na região do Banhado, São José dos Campos/SP, setembro/2017.

\begin{tabular}{lcccc}
\hline Parâmetros & Unidade & $\begin{array}{c}\text { Resultados } \\
\text { P1 }\end{array}$ & $\begin{array}{c}\text { Resultados } \\
\text { P2 }\end{array}$ & $\begin{array}{c}\text { Valor de Ref. } \\
\text { de qualidade* }\end{array}$ \\
\hline Fósforo & $\mathrm{mg} / \mathrm{kg}$ & 20,5 & 9,41 & - \\
Cálcio & $\mathrm{mg} / \mathrm{kg}$ & 494,5 & 292,1 & - \\
Magnésio & $\mathrm{mg} / \mathrm{kg}$ & 130,3 & 23,6 & - \\
Potássio & $\mathrm{mg} / \mathrm{kg}$ & 123,7 & 25,1 & - \\
Zinco & $\mathrm{mg} / \mathrm{kg}$ & $<0,007$ & $<0,007$ & 60 \\
Cobre & $\mathrm{mg} / \mathrm{kg}$ & 0,56 & $<0,004$ & 35 \\
Boro & $\mathrm{mg} / \mathrm{kg}$ & 2,51 & 1,69 & - \\
Ferro & $\mathrm{mg} / \mathrm{kg}$ & 59,5 & 59,5 & - \\
Manganês & $\mathrm{mg} / \mathrm{kg}$ & 2,87 & 2,82 & - \\
Nitrogênio total & $\mathrm{mg} / \mathrm{kg}$ & 390 & 127,1 & - \\
pH & $\mathrm{UpH}$ & 6 & 6,3 & - \\
Umidade & $\%$ & 69,4 & 36,16 & - \\
\hline \multicolumn{4}{c}{} \\
& $*$ de acordo com CONAMA (2009) e CETESB $(2014)$ &
\end{tabular}

Sabe-se que o valor agrícola dos solos que variam entre o orgânico e o de aluvião é alto, caso desta área do Banhado. Os solos aí existentes, pela presença de oxigênio e acúmulo de matéria orgânica, possuem alta fertilidade natural, propiciando o cultivo de hortaliças e culturas anuais, estando a maior parte coberta por vegetação espontânea e pastagens cultivadas (FLORIANO, 2009).

De acordo com a Resolução no 357 do CONAMA (2005), as águas da bacia do Banhado utilizadas para a irrigação das hortaliças pertencem a Classe II da classificação de Águas Doce.

Na Tabela 2 estão apresentados os parâmetros físico-químicos da qualidade da água na região da nascente, local da captação para o seu uso na irrigação das hortaliças do Banhado.

Tabela 2. Parâmetros físico-químicos da água no Banhado, São José dos Campos/SP, setembro/2017.

\begin{tabular}{lccc}
\hline Parâmetro & Dados de coleta & LQ & VMP (Conama) \\
\hline $\mathrm{pH}(\mathrm{UpH})$ & 6,8 & - & $6-9$ \\
Condutividade $(\mu \mathrm{S} / \mathrm{cm})$ & 372,05 & 0,113 & - \\
Demanda Bioquímica do Oxigênio $(\mathrm{mg} / \mathrm{L})$ & $<1,13$ & 1,13 & $<5 \mathrm{mg} / \mathrm{L}$ \\
Oxigênio Dissolvido $(\mathrm{mg} / \mathrm{L})$ & 9,64 & - & $>5 \mathrm{mg} / \mathrm{L}$ \\
Demanda Química do Oxigênio $(\mathrm{mg} / \mathrm{L})$ & $<12$ & 12 & - \\
Solução em n-hexano (mg/L) & $<5$ & 5 & - \\
Turbidez (UNT) & 1,6 & 0,5 & até $100 \mathrm{UNT}$ \\
Nitrogênio Total (mg/L) & 21,5 & - & $<3,7 \mathrm{mg} / \mathrm{L}$ \\
Fósforo (mg/L) & 0,12 & 0,053 & $<0,05$ \\
Zinco (mg/L) & $<0,007$ & 0,007 & 0,18 \\
Coliformes totais (NMP/100 mL) & $>16.000$ & $<1,8$ & - \\
Coliformes termotolerantes (NMP/100 mL) & 5.400 & $<1,8$ & até $1000 / 100 \mathrm{~mL}$ \\
\hline
\end{tabular}

LQ (Limite de quantificação); VMP (Valor Máximo Permitido) 


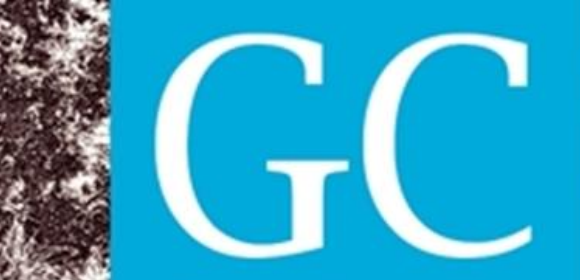

Revista Nacional de

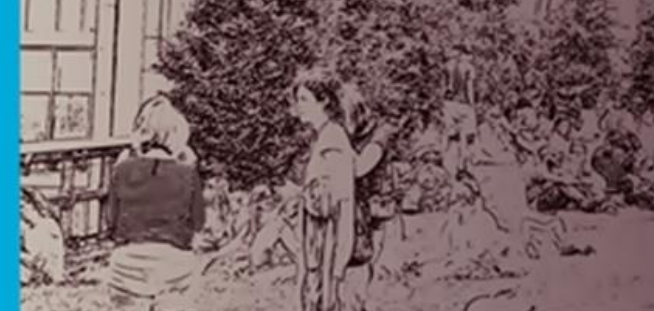

ISSN $2318-8472$

v. 06, n. 40,2018

Gerenciamento de Cidades

National Journal of Citiex Management

De maneira geral, os parâmetros estão dentro da regularidade, sendo importante, porém, destacar que o nitrogênio total, o fósforo e os coliformes termotolerantes estão acima do valor máximo permitido (VMP) pelo CONAMA (2005). De acordo com Barros et al. (2011), a produção de efluentes orgânicos, como fertilizantes e o despejo de esgotos residenciais contribuem para a elevação das taxas de nitrogênio total, mas neste caso, também pode-se supor que o esterco utilizado para a adubação da horta tenha ocasionado estas irregularidades.

Tendo em vista a presença de coliformes termotolerantes na água de irrigação, foi avaliada a sua ocorrência em alface in natura produzida no Banhado (Tabela 3). Diferentemente do que poderia se esperar, não houve a presença de coliformes termotolerantes nos vegetais, apenas de coliformes totais. A legislação brasileira (BRASIL, 2001) por meio da RDC $n$ ㅇ 12, de 2 de janeiro de 2001, estabelece limites microbiológicos para coliformes termotolerantes em hortaliças in natura podendo apresentar até $100 \mathrm{NMP} / \mathrm{g}$. 


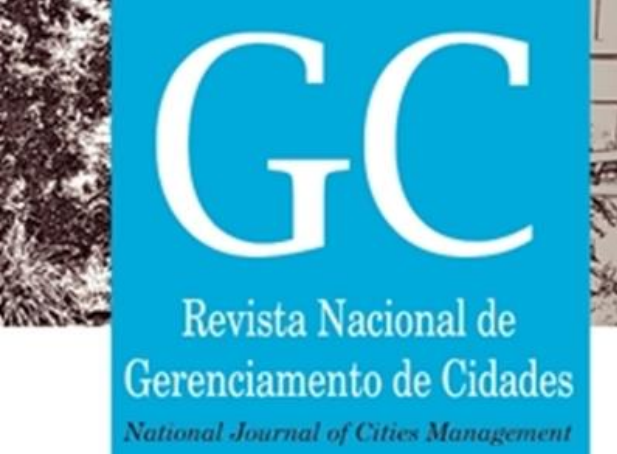

A ocupação irregular e a antropização de áreas protegidas e que deveriam estar tuteladas pelo governo, refletem em aumentos exorbitantes nas despesas da gestão municipal, necessitando de medidas intensivas de tratamento de água para o abastecimento público. Tal ocorrência deveria promover incentivos para a manutenção e conservação de nascentes e fontes, já que os danos podem muitas vezes serem irreversíveis, fato este não observado pela prefeitura de São José dos Campos. É conhecido hoje, que o tratamento de $1000 \mathrm{~m} 3$ de água em regiões pouco ou nada impactadas tem um custo de US\$ 2,00, enquanto que para a água degradada de regiões antropizadas o custo é de US\$8,00 (TUNDISI; BARBOSA, 1995).

No Brasil, o quadro de insuficiência de política habitacional de baixa renda, a enorme demanda por moradia de baixo custo, o crescente valor de uma boa localização no contexto intraurbano, graças ao crescimento do trabalho informal e à baixa qualidade do transporte público, além da insuficiência do controle urbanístico e poder de polícia do Estado alimentam o processo de ocupação urbana de áreas ambientalmente frágeis e com vantagens locacionais se comparadas à periferia (FREITAS, 2014). Exemplo disso é o que ocorre na área do Banhado, que por possuir uma localização central, seus habitantes resistem a desocupação proposta pela Prefeitura de São José dos Campos, preferindo viver em situação precária (O VALE, 2014).

Portanto, não se trata de coincidência o fato de que condições de precariedade social e urbana coexistem com ecossistemas de grande fragilidade ambiental (FREITAS, 2014). Davis (2006) elabora essa questão ao defender que, por traz desta coincidência atuam as leis de mercado, no caso o mercado de terras. Territórios com características desfavoráveis à urbanização são menos valorizados, e com frequência são deixados de lado pelos projetos de parcelamento da cidade. Entretanto, a enorme demanda habitacional de baixa renda reprimida pela atuação elitista do mercado imobiliário formal, torna esses espaços desprezados uma oportunidade de moradia de baixo custo. Isso porque eles possuem uma característica essencial para a sobrevivência da população de baixa renda na cidade: a proximidade com os bairros de maior renda, que concentram oportunidade de empregos e geração de renda.

É facilmente perceptível nas áreas urbanas de grandes cidades a valorização do espaço em virtude da localização do terreno sem que se leve em consideração aspectos imensuráveis economicamente como atributos naturais, históricos ou paisagísticos. Pelas características de seu solo e de suas condições hídricas, a área do Banhado apresenta alta vulnerabilidade e fragilidade, com vários problemas de drenagem pela proximidade do lençol na superfície, apresentando alta restrição à implantação de usos urbanos (FLORIANO, 2009).

Ciente dos danos ambientais presentes no Banhado, em São José dos Campos, na Figura 3 está apresentada uma matriz FOFA, que representa uma ferramenta de gestão ambiental, capaz de direcionar alguma atividade de intervenção ou possibilitar a previsão de efeitos futuros relacionados aos recursos ambientais. 


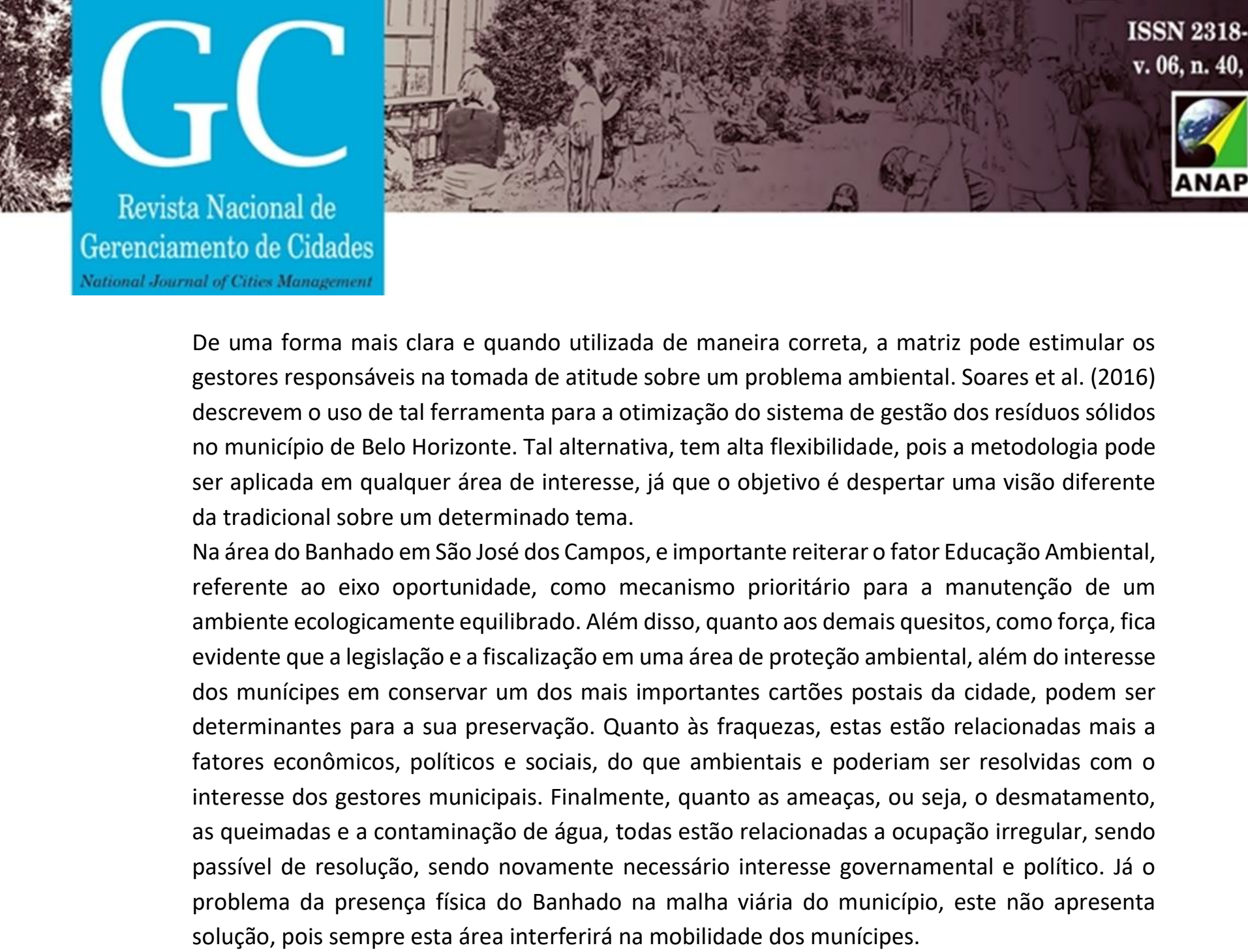
solução, pois sempre esta área interferirá na mobilidade dos munícipes. 
Figura 3: Matriz FOFA da relação ambiental no Parque do Banhado, São José dos Campos, SP, 2017.
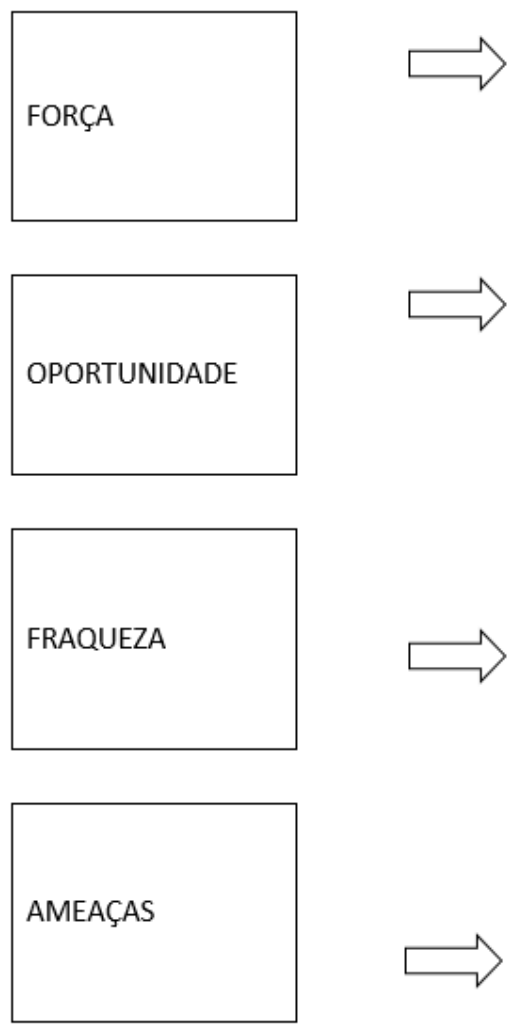

Fonte: os autores

\begin{tabular}{|l|}
\hline Amparo legal (criação da APA e PNMB) \\
\hline Fiscalização municipal (impedimento da expansão urbana) \\
\hline A água é um elemento essencial a vida
\end{tabular}

\begin{tabular}{|l|}
\hline Rede aberta para implantação de Educação Ambiental \\
\hline Turismo ecológico - cartão postal da cidade \\
\hline Agroecologia
\end{tabular}

\begin{tabular}{|l|}
\hline Desvalorização imobiliária local \\
\hline Fatores sociais - insegurança (tráfico de drogas) \\
\hline Descrédito ao direito ambiental \\
\hline
\end{tabular}

\begin{tabular}{|l|}
\hline Desmatamento/queimadas \\
\hline Contaminação da água \\
\hline Ocupação irregular \\
\hline Malha viária \\
\hline
\end{tabular}

\section{CONCLUSÃO}

O Banhado de São José dos Campos inicialmente designado como área de preservação ambiental e mais recentemente parque natural, tem sofrido significativas alterações ambientais ao longo dos anos, além da ocupação urbana, que caso não seja controlada, poderá colocar o ecossistema em risco.

A ocupação e o uso do solo no Banhado devem ser adequados às propriedades específicas de cada parcela da área, cabendo ao poder público, pelos estudos e leis, indicar as intervenções eficientes e priorizar as de uso rural ou ecológico que, como demonstrado, geram impactos positivos ou mínimos impactos negativos, de forma a preservar as funções histórica, social, paisagística e cultural desse espaço geográfico tão valioso.

Quanto a produção de hortaliças, é necessário preservar as fontes de água combatendo a entrada de esgoto clandestino, as fossas negras e a poluição difusa, desenvolvendo técnicas de tratamento de efluentes, visto haver a possibilidade de transmissão de doenças para seus consumidores. 
Obviamente que a atividade produtiva, por sua função social, pode e deve ser promovida, visto haver pessoas que há mais de 40 anos trabalham no local, mas a preocupação com o cenário ambiental não deve ficar em segundo plano, em vista da grande relevância ecológica do Banhado como ecossistema natural e de peculiar beleza cênica para a cidade de São José dos Campos e seus habitantes.

\section{REFERÊNCIAS}

ANVISA - AGÊNCIA NACIONAL DE VIGILÂNCIA SANITÁRIA. Resolução n. 12, de 02 de janeiro de 2001. Diário Oficial da União, Brasília, DF, União de 02 de janeiro de 2001. Disponível em: <http://elegis.bvs.br/leisref/public/showAct.php?id=144>. Acesso em: set. 2017.

APHA - AMERICAN PUBLIC HEALTH ASSOCIATION; AWWA - AMERICAN WATER WORKS ASSOCIATON; WEF - WATER ENVIRONMENT ASSOCIATION. Standard methods for the examination of water \& wastewater. 22st edition. Washington, 2012. $1496 \mathrm{p}$.

ARBOS, K. A.; FREITAS, R. J. S.; STERTZ, S. C.; CARVALHO, L. A. Segurança alimentar de hortaliças orgânicas: aspectos sanitários e nutricionais. Ciência e Tecnologia de Alimentos, v. 30, supl. 1, p. 215-220, 2010.

BARROS, R.V.G.B.; SOUZA, H. M. L.; SOUZA, C. A. Determinação do índice de qualidade da água (IQA) na sub-bacia do córrego André. Engenharia Ambiental: Pesquisa e Tecnologia, v. 8, n. 3, p. 138 -153, 2011. Disponível em: <http://ferramentas.unipinhal.edu.br/engenhariaambiental/viewarticle. php?id=584>. Acesso em: set. 2017.

BRASIL. Ministério da Saúde, Agência Nacional de Vigilância Sanitária. Resolução - RDC no12, de 02 de janeiro de 2001. Aprova o regulamento técnico sobre padrões microbiológicos para alimentos. Diário Oficial da União, Poder Executivo, Brasília, DF, 10 jan. 2001. Disponível em: <http://portal.anvisa.gov.br/documents/33880/ 2568070/RDC_12_2001.pdf/15ffddf6-3767-4527-bfac-740a0400829b>. Acesso em: 03 jan. 2018.

BRITO, L. T. L.; SRINIVASAN, V. S.; SILVA, A. de S.; GHEYI, H. R.; GALVÃO, C. DE O.; HERMES, L. Influência das atividades antrópicas na qualidade das águas da bacia hidrográfica do Rio Salitre. Revista Brasileira de Engenharia Agrícola e Ambiental, v.9, n.4, p.596-602, 2005.

CABRAL, J. P. S. Water microbiology. Bacterial pathogens and water. International Journal of Environmental Research and Public Health, v.7, n.10, p.3657-3703, 2010.

CETESB - Companhia Ambiental do Estado de São Paulo. Qualidade das águas interiores do estado de São Paulo, 2016. São Paulo, CETESB, 2017. 281p. Disponível em: <http://cetesb.sp.gov.br/aguas-interiores/wp-content/ uploads/sites/12/2013/11/Cetesb_QualidadeAguasInteriores_2017_02-06_VF.pdf>. Acesso em: 08 jan. 2018.

CETESB - Companhia Ambiental do Estado de São Paulo. Decisão de Diretoria no 045/2014/E/C/I, de 20 de fevereiro de 2014. Dispõe sobre a aprovação dos Valores Orientadores para Solos e Águas Subterrâneas no Estado de São Paulo - 2014, em substituição aos Valores Orientadores de 2005 e dá outras providências. Diário Oficial Estado de São Paulo - DOU/SP, Caderno Executivo I, n. 124, 36, (2014) 53. Disponível em: http://sites.usp.br/sef/wpcontent/uploads/sites/52/2015/03/47-CETESB2014_Valores_Orientadores_solo_agua.pdf>. Acesso em: $10 \mathrm{dez}$. 2017.

CONAMA - Conselho Nacional do Meio Ambiente. Resolução no 357, de 17 de março de 2005. Alterada pela Resolução 410/2009 e pela 430/2011. Dispõe sobre a classificação dos corpos de água e diretrizes ambientais para o seu enquadramento, bem com o estabelece as condições e padrões de lançamento de efluentes, e dá outras providências. Diário Oficial da União, Brasília, DF, n.53, de 18/03/2005, págs. 58-63. Disponível em: <http://www.mma.gov.br/port/conama/res/res05/res35705.pdf>. Acesso em: 10 jan. 2018. 
CONAMA - Conselho Nacional do Meio Ambiente. Resolução no 420, de 28 de dezembro de 2009. Alterada pela Resolução CONAMA no 460/2013 (altera o prazo do art. 8o, e acrescenta novo parágrafo). Dispõe sobre critérios e valores orientadores de qualidade do solo quanto à presença de substâncias químicas e estabelece diretrizes para o gerenciamento ambiental de áreas contaminadas por essas substâncias em decorrência de atividades antrópicas. Diário Oficial da União, Brasília, DF, n.249, de 30/12/2009, págs. 81-84. Disponível em: <http://www.mma.gov.br/port/conama/legiabre.cfm?codlegi=620>. Acesso em: 10 jan. 2018.

CUNHA, A. C; CUNHA, H. F. A.; BRASIL JR., A. C. P; DANIEL, L. A; SCHULZ, H. E. Qualidade microbiológica da água de rios de áreas urbanas e periurbanas no baixo Amazonas: o caso do Amapá. Revista de Engenharia Sanitária e Ambiental, Rio de Janeiro, v. 9, n. 4, p. 322-328, 2004.

DAVIS, M. Planeta favela. São Paulo: Boitempo, 2006.

DIAGNÓSTICO SÍNTESE. Plano Diretor de São José dos Campos. 2017. Secretaria de Urbanismo e Sustentabilidade PMSJC. Disponível em: <http://planodiretor.sjc.sp.gov.br/resources/uploads/EstudoTecnico/Anexo/ SINTESE\%20GERAL_7dez.pdf>. Acesso em: 10 jan. 2018.

FLORIANO, S. P. Uso e ocupação do solo na Área de Proteção Ambiental do Banhado em São José dos Campos-SP. Revista Paisagens, VIII, p. 56-61, $2009 . \quad$ Disponível em: <https://www.revistas.usp.br/revistapaisagens/article/view/133059/129132>. Acesso em: 20 nov. 2017.

FREITAS, C. F. S. Ilegalidade e degradação em Fortaleza: os riscos do conflito entre a agenda urbana e ambiental brasileira. Urbe, Revista Brasileira de Gestão Urbana, Curitiba, v. 6, n. 1, p. 109-125, 2014.

FREITAS, E. V. C; BARRETO, F. M. S; NUNES, A. B. A; ALENCAR, M. F. Índice de Qualidade da Água Bruta do Açude Gavião - Município de Pacatuba. Anais. 26 Congresso Brasileiro de Engenharia Sanitária e Ambiental (2011).

G1 - Vale do Paraíba e Região. PM prende chefe do tráfico de drogas na região central de São José. 2014. Disponível em: <http://g1.globo.com/sp/vale-do-paraiba-regiao/noticia/2014/04/pm-prende-chefe-do-trafico-de-drogas-naregiao-central-de-sao-jose.html>. Acesso em: 15 dez. 2017.

GOOGLE MAPS. Banhado - Cartão Postal de São José dos Campos. 2018. https://www.google.com.br/maps/place/BANHADO+-+CART\%C3\%830+POSTAL+DE+S\%C3\%830+JOS\%C3\%89+DOS +CAMPOS/@-23.1812939,-45.9089887,4072m/data=!3m1!1e3!4m5!3m4!1s0x94cc4a05bf0d5723:0x659eb147f3b $15 \mathrm{a} 2 \mathrm{~b} ! 8 \mathrm{~m} 2$ !3d-23.185858!4d-45.8979513?hl=pt-BR

GOVERnO do ESTAdO DE SÃO PAULO. Sistema Ambiental Paulista. Sobre a APA. 2017. Disponível em: <http://www3.ambiente.sp.gov.br/apa-banhado/sobre-a-apa/>. Acesso em: 15 dez. 2017.

IBGE - INSTITUTO BRASILEIRO DE GEOGRAFIA E ESTATístICA. Cidades. 2017. Disponível em: $<$ https://cidades.ibge.gov.br/brasil/sp/sao-jose-dos-campos/pesquisa/23/25359?detalhes=true>. Acesso em: 20 nov. 2017.

LUCAS, A. A. T.; FOLEGATTI, M. V.; DUARTE, S. N. Qualidade da água em uma microbacia hidrográfica do Rio Piracicaba, SP. Revista Brasileira de Engenharia Agrícola e Ambiental., v. 14, n. 9, p. 937-943, 2010.

MMA - MINISTÉRIO DO MEIO AMBIENTE. Secretaria de Biodiversidade e Florestas. Departamento de Áreas Protegidas. Cadastro Nacional de Unidades de Conservação. Relatório Parametrizado. Unidade de Conservação: Parque Natural Municipal do Banhado. 2018. Disponível em: <http://sistemas.mma.gov.br/cnuc/index.php ?ido=relatorioparametrizado.exibeRelatorio\&relatorioPadrao=true\&idUc=2727>. Acesso em: 03 jan. 2018.

MORELLI, A. F. Identificação e Transformação das Unidades da Paisagem no Município de São José dos Campos (SP) de 1500 a 2000. Rio Claro, 2002. 404 p. Tese (Doutorado em Geociências e Meio Ambiente) - Instituto de Geociências e Ciências Exatas de Rio Claro. 2002. Universidade Estadual Paulista "Júlio de Mesquita Filho". Disponível em: <https://pt.slideshare.net/afmorelli/tese-morelli-completa-01052005-para-internet>. Acesso em: 20 nov. 2017. 
MORELLI, A. F.; CAVALHEIRO, F.; ALVES, M. A.; FANTIN, M. Representação espacial da cobertura vegetal natural original do município de São Jose dos Campos (SP). In: Simpósio Brasileiro de Sensoriamento Remoto, 11., 2003, Belo Horizonte. Anais... São Jose dos Campos: INPE, 2003, p. 681-689. Disponível em: <http://marte.sid.inpe.br/col/ltid.inpe.br/sbsr/2002/11.18.01.47/doc/06_367.pdf>. Acesso em: 20 nov. 2017.

MORELLI, A. F.; SANTOS, A. P. O Banhado de São José dos Campos: Caracterização de um patrimônio Valeparaibano. In: SEMINÁRIO NACIONAL- O Estudo da História na Formação do Arquiteto, FAUUSP, Anais... São Paulo, 9-12 de out, São Paulo, 1994.

OLIVEIRA, M. L. S.; LOURENÇO, L. F. H.; LOURENÇO, V. V. Análise microbiológica de alface (Lactuta sativa,L.) e tomate (Solanum lycopersicum, L.), comercializados em feiras-livres da cidade de Belém, PA. Higiene Alimentar. 20(143): 96101, 2006. Disponível em: <http://pesquisa.bvsalud.org/bvs-vet/resource/pt/vti-13113>. Acesso em: 20 nov. 2017.

O VALE. Prefeitura planeja desocupar o Banhado até o início de 2015. 2014. Disponível em: <http://www2.ovale.com.br/prefeitura-planeja-desocupar-o-banhado-ate-o-inicio-de-2015-1.557494>. Acesso em: 15 dez. 2017.

PREFEITURA SÃO JOSÉ DOS CAMPOS. Parque do Banhado. 2017. Disponível em: <http://servicos2. sjc.sp.gov.br/secretarias/urbanismo_sustentabilidade/parque_do_banhado.aspx>. Acesso em: 15 dez. 2017.

ROSA FILHO, A. As políticas públicas do poder executivo na remoção e/ou reurbanização de favelas no Município de São José dos Campos-SP. Dissertação (Mestrado em Planejamento Urbano e Regional) - Instituto de Pesquisa e Desenvolvimento, Universidade do Vale do Paraíba, São José dos Campos, 2002. Disponível em: <http://biblioteca.univap.br/dados/000000/0000008A.PDF>. Acesso em: 15 dez. 2017.

SANTOS, A. P. S.; GUTLICH, G. R.; MORELLI, A. F.; MOURÃO, F. B. Planejamento metropolitano e preservação da paisagem natural: o caso da várzea do rio Paraíba do Sul e o Banhado de São José dos Campos, SP. In: VII Seminário Internacional sobre Desenvolvimento Regional, Anais... Santa Cruz do Sul, RS, p. 1-23, 2015.

SANTOS, Y. O.; ALMEIDA, R. C. C.; GUIMARÃES, A. G.; ALMEIDA, P. F. Higienic sanitary quality of vegetables and evaluation of treatments for the elimination of indigenous $E$. coli and $E$. coli $0157: \mathrm{H} 7$ from the surface of leaves of lettuce (Lactuca sativa L.). Ciência e Tecnologia de Alimentos, Campinas, v.30, n.4, p.1083-1098, 2010.

SÃO PAULO (Estado). Lei Estadual no 11.262, de 08/11/2002. Declara Áreas de Proteção Ambiental o trecho da Serra da Mantiqueira e as áreas urbanas no Município de São José dos Campos, Diário Oficial, São Paulo, p. 3, 2002.

SILVA, D. A.; VIANNA, P. C.; ZANETTI, V. Planejamento urbano, agentes e representações: criação do banhado, cartão postal de São José dos Campos. Ambiente \& Sociedade, v. 20, n.2, p. 163-184, 2017.

SOARES, D.; MARQUES, H.; CHAVES, O.; ZAGO, V. Diagnóstico para a otimização do sistema de gestão dos resíduos sólidos na Regional Centro-Sul do Município de Belo Horizonte: uma análise das forças e fraquezas, oportunidades e ameaças. GOT, n. 10, p. 319-343, 2016.

SOMAR METEOROLOGIA. Dados observados - São José do Campos. 2017. Disponível em: $<$ http://somarmeteorologia.com.br/security/defesa_civil/mapas.php?cid=SaoJosedosCampos-

SP\&mes=08\&ano=2017>. Acesso em: $15 \mathrm{dez} .2017$.

SOUZA, H. M. L.; NUNES, J. R. S. Avaliação dos parâmetros físico-químicos e bacteriológicos do córrego Figueira pertencente a microbacia do queima-pé de Tangará da Serra/MT. Engenharia Ambiental: pesquisa e tecnologia, v. 5, $\mathrm{n} \mathrm{2,} \mathrm{p} \mathrm{110-124,} \mathrm{2008.} \mathrm{Disponível} \mathrm{em:} \mathrm{<http://ferramentas.unipinhal.edu.br/engenhariaambiental}$ /viewarticle.php?id=123>. Acesso em: $15 \mathrm{dez} .2017$.

TUNDISI, J. G.; BARBOSA, F. A. R. Conservation of Aquatic ecosystems: present status and perspectives 1995. In: Tundisi, J. G.; Bicudo, C. E. M.; Matsumara Tundisi, T. (eds.). Limnology in Brazil. 1995. Brazilian Limnological Society. 